\title{
Comunidade, espaço e sobrevivência: as imagens-devir dos quilombolas do Sapê do Norte
}

\section{Community, space and survival: the images-become of Sapê do Norte's quilombolas}

\begin{abstract}
Isabel Stein ${ }^{1}$
Resumo: Este artigo pretende explorar possibilidades estéticas e políticas na investigação de imagens de um tipo de formação social nacional: as comunidades quilombolas. Com este objetivo, as fotografias presentes no projeto Cartografia Social das Comunidades Quilombolas e o Carvão no Sapê do Norte serão analisadas e discutidas, de forma a sugerir que no lugar de uma identidade quilombola calcada em conceitos teleológicos e fixos - exaustivamente trabalhados por teorias pós-coloniais fundadas no multiculturalismo - como, por exemplo, filiação, território e memória, essas comunidades podem, atualmente, manifestar uma existência configurada por outros paradigmas: comunidade, espaço e sobrevivência.
\end{abstract}

Palavras-chave: comunidades e paisagens culturais, grupo minoritário, fotografia.

\begin{abstract}
This article intends to explore aesthetic and political possibilities in the investigation of images of a kind of national social formation: the quilombola communities. With this aim, the photographs presented in the project Cartografia Social Quilombola e o Carvao no Sapê do Norte will be analyzed and discussed, in order to suggest that instead of a quilombola identity based on teleological and fixed concepts - exhaustively worked by postcolonial theories based on multiculturalism - such as affiliation, territory, and memory, these communities can now manifest an existence shaped by other paradigms: community, space, and survival.
\end{abstract}

Keywords: communities and cultural landscapes, minority groups, photography.

\section{Introdução}

O Brasil possui, aproximadamente, três mil comunidades quilombolas distribuídas por quase todos os Estados da federação. Essas comunidades são grupos étnicos que descendem de moradores dos quilombos, locais de resistência autônoma de escravos, que sugiram entre os séculos XVI e XIX. Atualmente, as comunidades quilombolas vivem um drama jurídico: por lei, toda comunidade reconhecida deve ter a titulação de seu território. O Artigo 68 do Ato das Disposições Constitucionais Transitórias (ADCT) diz que:

\footnotetext{
${ }^{1}$ Isabel Stein é mestre em Comunicação e Cultura pela Universidade Federal do Rio de Janeiro. Contato: belaslstein@gmail.com
} 
Aos remanescentes das comunidades dos quilombos que estejam ocupando suas terras é reconhecida a propriedade definitiva, devendo o Estado emitir-lhes os respectivos títulos (2016).

Vale acrescentar que a partir de 2003, o Incra (Instituto Nacional de Colonização e Reforma Agrária) passou a ser o órgão responsável pela titulação de terras quilombolas. Contudo, na prática, muitas não obtiveram o reconhecimento do Estado, e mesmo dentre as que são reconhecidas, poucas receberam, de fato, o título definitivo de propriedade.

A região do Sapê do Norte, que abrange os municípios de São Mateus e Conceição da Barra, no nordeste do Espírito Santo (Figura 1), abrigava, antes da década de 1970, aproximadamente 100 comunidades quilombolas. Durante a ditadura militar, o estímulo à produção da monocultura do eucalipto, para produção, inicialmente, de carvão e madeira, e posteriormente, de celulose, levou a empresa Aracruz ao Sapê do Norte. Desamparados por uma lei fantasma e ilhados em um "deserto verde", como chamam, composto de uma natureza não natural, os quilombolas da região foram reduzidos a quinta parte, organizados em pouco mais do que duas dezenas de comunidades. Com o espaço invadido pelo eucalipto, a produção agrícola de subsistência tornou-se inviável, tanto pela falta de espaço, como pela qualidade do solo, destruído pela monocultura. Transformados em um incômodo material e político, os moradores das comunidades convivem com a vigilância constante da indústria (atualmente, intitulada Fibria), que tem como objetivo encontrar motivos legais para criminalizá-los. Diante da situação em que se encontram, não é incomum que eles retirem árvores de eucalipto, que são plantadas até mesmo dentro do quintal das casas. Além disso, a produção de carvão - que é levado para venda no Sudeste por atravessadores - tornou-se a única forma de sobrevivência encontrada pelos quilombolas da região. Para este fim, os restos dos troncos de eucalipto são utilizados como matéria prima. Neste contexto, os moradores são frequentemente enquadrados por roubo de madeira e por formação de quadrilha. Portanto, a repressão policial é constante.

Em relação à identidade quilombola, o texto encontrado na Regularização de Território Quilombola: Perguntas e Respostas, documento oficial do Incra, afirma que:

O termo quilombo é uma categoria jurídica usada pelo Estado brasileiro a partir da Promulgação da Constituição Federal de 1988, visando assegurar a propriedade definitiva às comunidades negras rurais dotadas de uma trajetória histórica própria e relações territoriais específicas, 


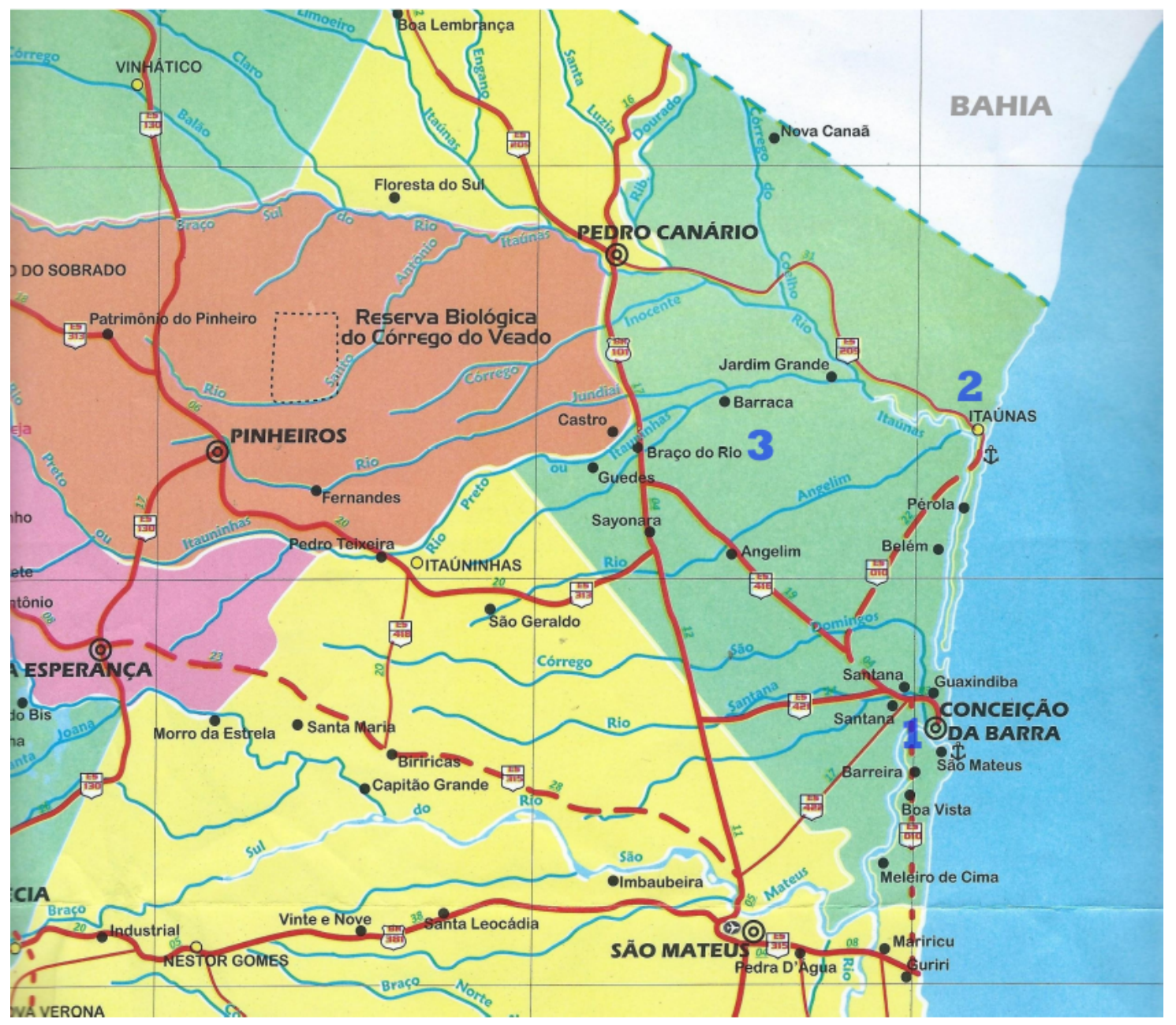

Figura 1. Mapa da região. Fonte: Agências Postais, disponível em http://agenciaspostais.com.br/?page_id=7452 
bem como ancestralidade negra relacionada com o período escravocrata (2014:4).

Três expressões podem ser destacadas no final deste trecho: trajetória histórica, relações territoriais e ancestralidade negra. Elas se relacionam diretamente com as categorias trabalhadas no presente artigo: memória, território e filiação. Ainda que a definição da comunidade quilombola passe por estes conceitos, seria possível pensar outros atravessamentos na vida destas pessoas? O exemplo das comunidades no Sapê do Norte parece deixar explícito tanto que estes conceitos, isoladamente, parecem não mais sustentar uma existência viável, como que as manifestações de resistência estão alocadas em outras relações. Ainda que talvez não tenham sido produzidas sob este viés, as fotografias do projeto Cartografia Social das Comunidades Quilombolas e o Carvão no Sapê do Norte causam um efeito que sugere tal interpretação.

\section{Materialidade e corporeidade vegetal: o comum nas fotografias sem rosto do Sapê do Norte}

O projeto Cartografia Social das Comunidades Quilombolas e o Carvão no Sapê do Norte $^{2}$, realizado em 2013, e coordenado pelo antropólogo Sandro José da Silva, expõe, através de imagens e textos, a complexa situação das comunidades quilombolas que vivem nesta região do nordeste capixaba. O projeto tem como objetivo mostrar, através do olhar de jovens da região, o caráter discriminatório da exploração econômica tanto étnico como racial. O projeto teve como resultado uma publicação que contextualiza historicamente a situação e mapeia as reivindicações das comunidades.

O trabalho é composto de 31 fotografias, que mostram as atividades dos quilombolas em diversas etapas da confecção do carvão (salvo por algumas poucas imagens de crianças em momentos de lazer). Parece pertinente sublinhar que das três dezenas de fotografias, 21 contém a presença humana, porém não mostram rostos. Neste ponto, é preciso estabelecer que este artigo não se propõe a investigar as condições de produção ou as motivações que teriam levado o fotógrafo a fazer esta escolha; ele limita-se a percorrer os efeitos que tais imagens produzem, e explorar as projeções simbólicas que

\footnotetext{
${ }^{2} \mathrm{O}$ projeto pode ser encontrado neste endereço eletrônico: https://issuu.com/rayzamucuna/docs/carto grafia_web, e as fotografias podem ser vistas, separadamente, neste endereço eletrônico: https://flickr.com/photos/96984791@N07/sets/72157633937584148.
} 
rasgam o tecido contingencial da existência quilombola, deixando entrever imaginários possíveis de passado e futuro.

Em seus primórdios, a fotografia assumiu a função - até então - pictórica de retratar. Mais tarde, começou a ser utilizada para fins policiais, na indexação de criminosos e suspeitos. Ainda na segunda metade do século XIX, o carte-de-visite tornou-se mundialmente popular, conferindo status a quem os obtivesse. Com diferentes finalidades, a imagem do rosto humano sempre incorporou a função indexical da identificação. Diarmuid Costello escreve, ao comentar os efeitos do olhar de rostos fotografados, em um artigo sobre a aura (Benjamin):

ele abre um momento de transcendência dentro do horizonte de consciência. [...] o olhar do outro vem para mim de dentro de meu mundo (consciência), apesar de ser um ponto de vista dele por fora, portanto, o transcendendo. Nesse sentido, o rosto do outro funciona como o limite do meu mundo: coloca a soberania da minha própria subjetividade em questão. O rosto é uma profilaxia contra o solipsismo (2005:20, tradução nossa).

Se o rosto é precisamente o que singulariza, o que faz perceptiva a alteridade, e, portanto, o que ativa nos indivíduos o senso comunitário (nesse sentido, em oposição ao solipsismo), o que dizem as fotografias sem rosto? Que percepções elas conduzem? Seguindo a lógica, por oposição, elas seriam, então, invariavelmente isolantes, uma vez que o confronto visual com a face da imagem não é possível. Porém, tal conclusão não se faz adequada, ao menos não em relação ao ensaio fotográfico aqui analisado.

Eduardo Viveiros de Castro e Déborah Danowski respondem a esta aparente contradição:

Pode ter havido uma humanidade de antes do mundo, mas não pode haver um mundo de depois da humanidade, um mundo, em suma, desprovido de relação e de alteridade (2014:106).

Embora em um primeiro momento a frase pareça corroborar a ideia de uma alteridade que seja irredutivelmente humana, a humanidade a qual Viveiros e Danowski se referem é antropomórfica, e não antropocêntrica:

A "humanidade" é assim ao mesmo tempo uma condição universal e uma perspectiva estritamente dêitica e auto-referencial. Espécies diferentes não podem ocupar o ponto de vista do "Eu" simultaneamente, devido à restrição dêitica: em todo confronto aqui-agora entre duas espécies, é forçoso que uma termine por impor a sua humanidade, isto é, que 
ela termine por fazer a outra "esquecer" sua própria humanidade. Nós humanos (i.e. nós ameríndios) não vemos os animais como humanos, portanto. Eles não são humanos-para-nós; mas nós sabemos que eles são humanos-para-si (2014:95).

Dessa forma, o que as fotografias sem rosto projetam não é a falta de alteridade, mas uma alteridade outra, vegetal, feita de um material que não é pele humana. Uma das imagens (Figura 2) mostra um menino deitado sobre uma pilha de troncos cortados. Devido a posição da câmera, o rosto dele não pode ser visto - sua perna direita, que encontra-se dobrada, o encobre. Se olhada com atenção, a fotografia permite formar no cérebro a figura humana, marcada pelas colorações de amarelo e azul, presentes nas roupas do garoto. Mas em um primeiro momento, qualquer observador vê uma pilha de troncos cortados - composta tanto por toras de madeira, quanto por membros humanos. Mesmo depois de alguns instantes, a sensação que, afinal, sedimenta no observador, é esta: a solidez confusa de uma pilha desorganizada de pedaços de madeira. Tudo, na imagem, é trabalhado para esta percepção: a cor, o gesto, o ângulo da câmera, o enquadramento. Aqui, devir-tronco e devir-perna se confundem. O menino passa a ser madeira e a madeira passa a ser pessoa.

Ainda sobre esta fotografia, outro aspecto atrelado à noção de identidade pode ser destacado: a figuração. A concepção antropocêntrica de sujeito presume, necessariamente, a existência de um corpo uno e constante. Contra essa ideia, Donna Haraway evoca, na construção do que chama de Chthuluceno ${ }^{3}$, a não-figura, ou anti-figura do Cthulhu, nomeado, de acordo com a autora,

\begin{abstract}
a partir dos diversos e abrangentes poderes e forças tentaculares, e a partir de uma coleção de coisas com nomes como Naga, Gaia, Tangaroa, Terra, Haniyasu-hime, Spider Woman, Pachamama, Oya, Gorgo, Raven, A'akuluujjusi, e muitos outros. "Meu" Chthulucene, ainda que sobrecarregado com seus problemáticos Greek-ish tentáculos, aporta infinitas temporalidades e espacialidades, e infinitas entidades intraativas, incluindo o mais-do-que-humano, outro-que-humano, inumano, e humano-como-humus. (2015:160, tradução nossa)
\end{abstract}

Viveiros de Castro também utiliza uma referência visual que resiste, de certa forma, ao determinismo figurativo: o xamã $\tilde{a}^{4}$ a quem se revelam agentes prosopomór-

\footnotetext{
${ }^{3}$ Haraway propõe esta nova era geológica, mais dinâmica e rizomática (Deleuze; Guattari), em uma espécie de resposta às ideias de Antropoceno e Capitaloceno (Moore, 2014).

${ }^{4}$ No livro Metafísicas Canibais, o xamanismo ameríndio é definido como "a habilidade manifesta por certos indivíduos de cruzar deliberadamente as barreiras corporais entre as espécies e adotar perspectiva
} 


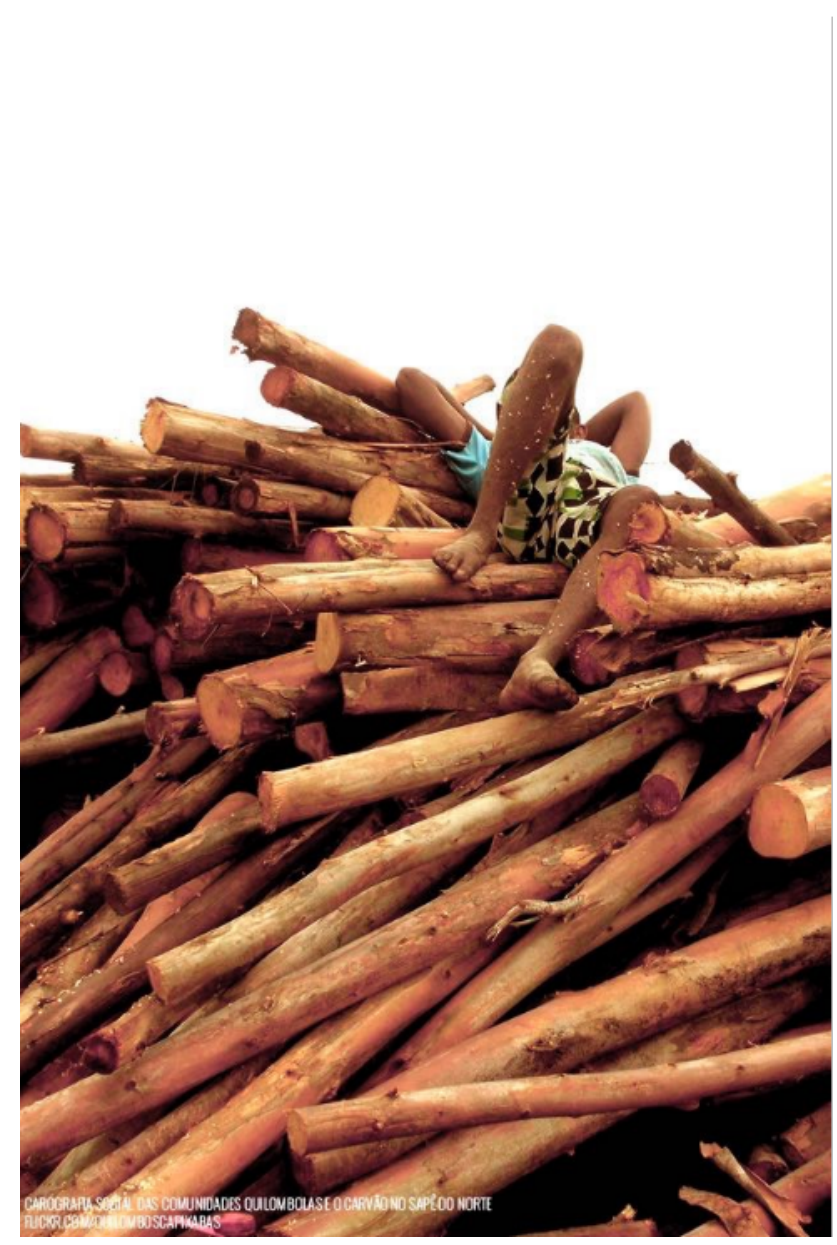

Figura 2. Cartografia Social das Comunidades Quilombolas e o Carvão no Sapê do Norte, disponível em https://www.flickr.com/photos/quilomboscapixabas/9039270344/

ficos.

A partir desta proposta de consciência identitária, que pode ser classificada como perspectivista (Viveiros de Castro), que lugar ideológico ocupam a ancestralidade, a filiação, a herança? James Clifford questiona, em seu livro The Predicament of Culture: Twentieth-Century Ethnography, Literature, and Art (1988):

Mas, e se a identidade for concebida, não como uma fronteira a ser defendida, e sim como um nexo de relacões e transacões no qual o sujeito está ativamente comprometido? A narrativa ou narrativas da interacão devem, nesse caso, tornar-se mais complexas, menos lineares e teleológicas. (Clifford apud Viveiros de Castro, 2016:196).

É evidente que a vivência quilombola é intensamente sustentada por estes valores. A recuperação e a manutenção de histórias familiares dos quilombos represende subjetividades 'estrangeiras', de modo a administrar as relações entre estas e os humanos.". (Viveiros de Castro, 2015:49) 
tam, indubitavelmente, uma questão central para a resistência étnica no país; mas que outros aspectos políticos, sociais, econômicos, culturais e ideológicos são levantados, atualmente, pela existência dessas comunidades? Que relações - não necessariamente submetidas ao crivo da hereditariedade - são construídas na existência dessas pessoas? Ainda, segundo Viveiros de Castro,

A humanidade é a posição do congênere, o modo reflexivo do coletivo, e como tal é derivada em relação às posições primárias de predador ou presa, que envolvem necessariamente outros coletivos, outras multiplicidades pessoais em situação de alteridade perspectiva. A semelhança ou congeneridade surge por suspensão deliberada, socialmente produzida, de uma diferença predatória dada; ela não a precede. (2015:47)

Levantadas estas questões, cabe refletir como elas se acoplam a outras teorias que envolvem concepções de comunidade e do comum. Pode-se citar, neste contexto, a linhagem de autores que contém como alguns de seus principais representantes Bataille, Blanchot, Esposito, Nancy, Agamben e, dentro do contexto brasileiro, Peter Pál Pelbart. Em seu livro La Comunidad Inoperante, Jean-Luc Nancy questiona:

próximo do tema do indivíduo, porém além dele, talvez deveria-se que desvelar a questão da singularidade. O que é um corpo, um rosto, uma voz, uma morte, uma escritura - não indivisíveis, se não singulares? Qual é a necessidade singular na partição que divide e que faz comunicar os corpos, as vozes, as escrituras, no geral e na totalidade? (2000:18, tradução nossa)

Ao discriminar a singularidade em corpo, rosto, voz, morte, o autor explicita a materialidade disto que chamamos de indivíduo. É precisamente por este viés que a fotografia do garoto na pilha de troncos atua. Ela traz materialidade ao corpo.

Alguma coisa do fundo sobe à superfície, e sobe sem tomar forma, insinuando-se entre as formas, existência autônoma sem rosto, base informal (Deleuze, 2000:352).

A imagem sugere uma existência que já não é mais possível, não é mais soberana sobre si mesma, naquelas condições. Prevê e condensa, em imagem, uma morte que não é "chorável"- nos termos de Judith Butler ${ }^{5}$. Mas a materialidade sugerida é uma materialidade vegetal, o que produz um escape, um imaginário de possibilidades outras,

\footnotetext{
${ }^{5} \mathrm{~A}$ imagem de um composto é utilizada, também, por Donna Haraway, ao comentar a extinção e a destruição de diversas espécies, e ao trabalhar o conceito de refugiado: "Eu sou uma compostista, não uma pós-humanista: todos somos compostos, não pós-humanos. [...] A extinção não é somente uma metáfora, o colapso do sistema não é um thriller. Pergunte a qualquer refugiado de qualquer espécie.". (2015:161, tradução nossa)
} 
vivências outras. Antes de representar um bloco de materiais, apresenta um composto ${ }^{6}$ de viventes, ainda que com a marca implacável do capital.

\section{Terra sem referência: a marca verde do capital}

Duas fotografias do ensaio chamam atenção pela paisagem saturada de árvores de eucalipto. Uma delas (Figura 3) mostra duas pessoas - uma mulher e um homem - de costas, andando por um caminho de terra. Ela apoia a mão direita no ombro esquerdo dele. A paisagem em que se encontram é formada por uma área central com alguns arbustos, onde pode-se ver uma névoa ao fundo, perto de uma pequena construção. Uma plantação de eucalipto cerca este local. Pela imagem, é possível deduzir que a vegetação rodeia toda a área.

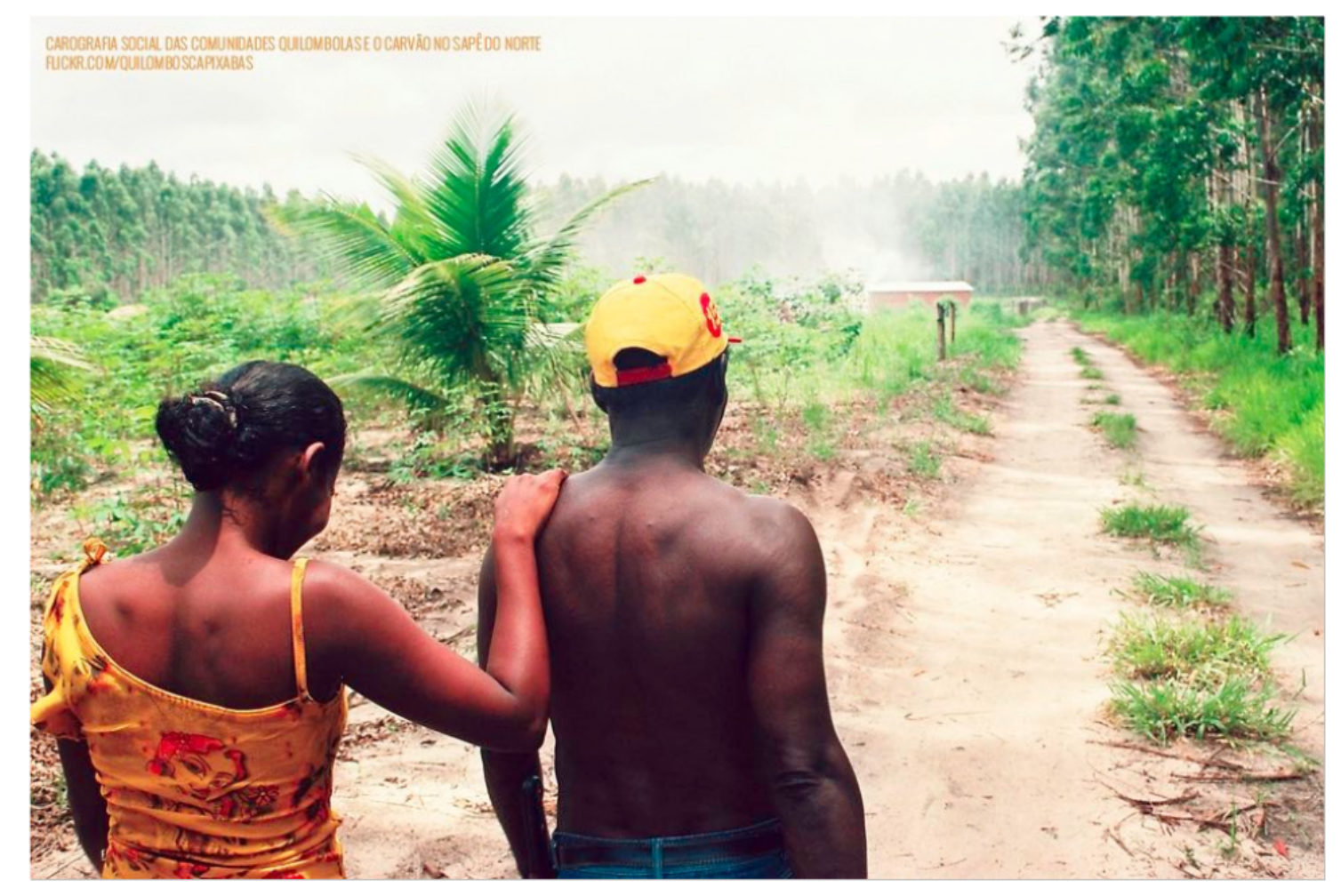

Figura 3. Fonte: Cartografia Social das Comunidades Quilombolas e o Carvão no Sapê do Norte, disponível em https://www.flickr.com/photos/quilomboscapixabas/9035106990/

A outra fotografia (Figura 4) mostra um guindaste durante o que parece ser 0

\footnotetext{
${ }^{6} \mathrm{~A}$ imagem de um composto é utilizada, também, por Donna Haraway, ao comentar a extinção e a destruição de diversas espécies, e ao trabalhar o conceito de refugiado: ?Eu sou uma compostista, não uma pós-humanista: todos somos compostos, não pós-humanos. [...] A extinção não é somente uma metáfora, o colapso do sistema não é um thriller. Pergunte a qualquer refugiado de qualquer espécie.". (2015:161, tradução nossa)
} 
processo de retirada dos troncos para alguma finalidade produtiva. A máquina encontrase ao lado de uma pilha de troncos cortados no chão. Ao fundo, pode-se ver uma floresta de eucaliptos. A composição é iluminada por uma forte luz, não natural, que poderia ter como fonte o farol do guindaste - que trabalha à noite - ainda que a iluminação intensa do próprio aparelho deixe dúvidas sobre isso.

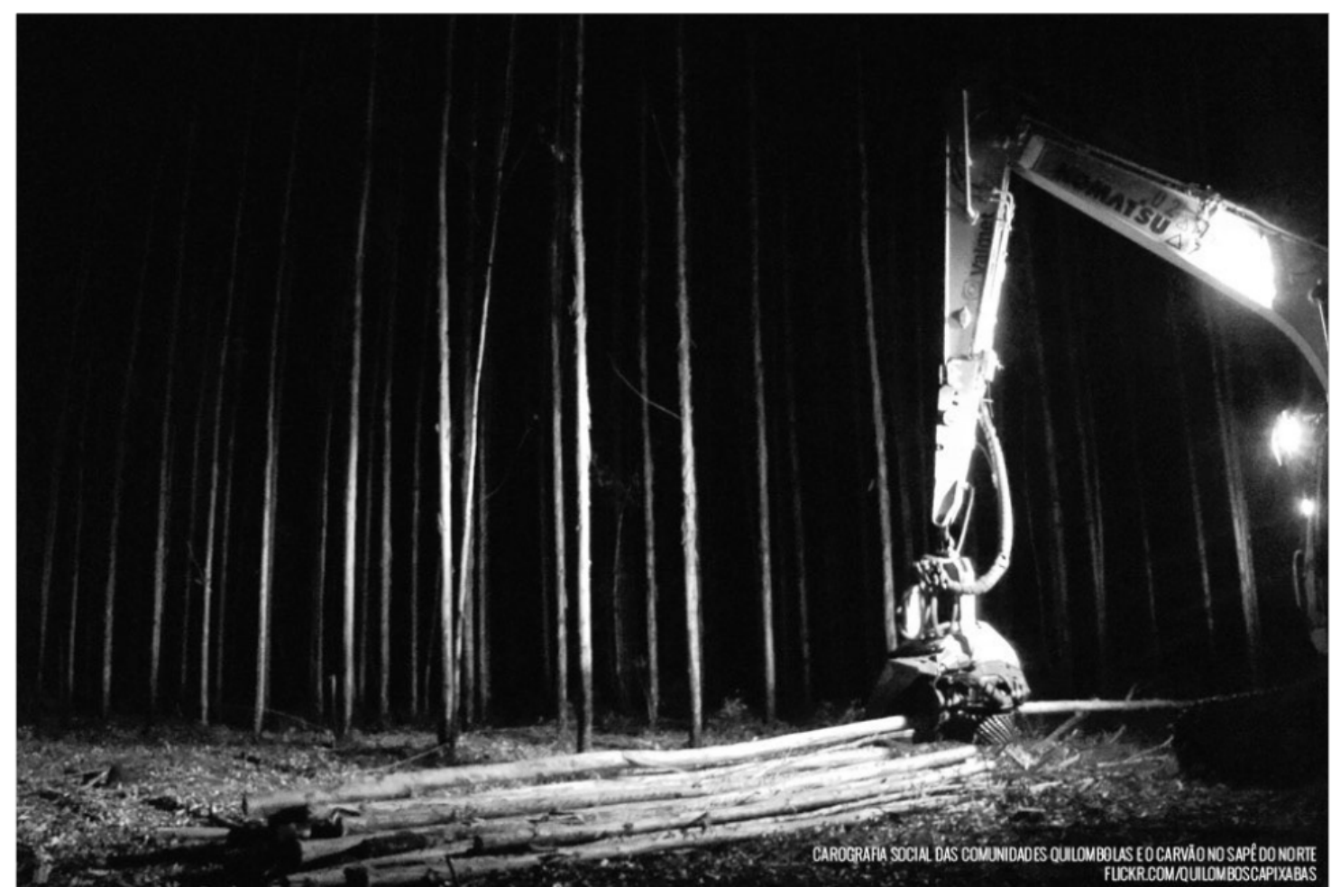

Figura 4. Fonte: Cartografia Social das Comunidades Quilombolas e o Carvão no Sapê do Norte, disponível em https://www.flickr.com/photos/quilomboscapixabas/9035106282/

Essas fotografias evocam uma relação completamente não referenciada com os ambientes, o que entra em embate com a pretensão dos quilombolas para a região. Para eles, aquela região tem relevância histórica, funciona como depósito cultural; é intrínseca a sua própria existência. Sua relação com aquele ambiente é territorialista. Aqui, tornase quase inevitável trazer a discussão sobre desterritorialização levantada em Mil Platôs por Deleuze e Guattari. David Lapoujade comenta:

Possuir um território, não é isso que pretende toda reivindicação, toda expressão? Toda reivindicação, toda pretensão não é, primeiro, territorial, territorializante? Chegar num meio, nele criar hábitos, nele inscrever suas marcas e suas referencias como delimitações, nele adotar condutas de acordo com determinados ritmo, em suma, compor um ritornelo, já não reivindicar um território, à maneira de um direito consuetudinário? Há reivindicação territorial assim que há composição de espaços-tempos 
determinados, mesmo quando provisórios ou móveis. A esse respeito, Mil Platôs pode dizer que o território é o primeiro de todos os agenciamentos. (2015:40)

No livro, há uma defesa explícita da desterritorialização como processo libertário em direção a espaços lisos ${ }^{7}$. É necessário que se faca, neste momento, dois esclarecimentos. Os termos "território", "desterritorialização", "terra" e afins são utilizados, por Deleuze e Guattari, em sentido irrestrito, em relação ao próprio plano ${ }^{8} \mathrm{em}$ que se inscreve a filosofia e o pensamento. No presente artigo, os termos são apropriados em uma versão mais literal; uma vez que o principal problema político dos quilombolas do Sapê do Norte (e de praticamente todas as comunidades do Brasil) é, de fato, a terra, a abstração destes conceitos não se faz necessária, ainda que esteja sempre implícita. Defende-se, aqui, que neste caso específico, a força do discurso torna-se ainda mais potente, quanto maior for sua atualização visual e sua coincidência com as questões extremamente materiais que envolvem as comunidades quilombolas no país. Com isso, passamos ao segundo esclarecimento: ao utilizar a filosofia de Deleuze e Guattari como prisma de leitura para as fotografias e para questão territorial quilombola não se pretende, em nenhuma hipótese, contestar as reivindicações das comunidades, mas sugerir que dada a situação de sufocamento em que se encontram, elas produziram uma outra relação espacial com a terra, cuja percepção é aberta, criada e imaginada pelas imagens aqui trabalhadas.

A partir de uma leitura de Deleuze e Guattari, Lapoujade afirma que o capitalismo é, necessariamente, desterritorializante, mas que, ao mesmo tempo, reterritorializa da forma que the convém:

Se o confronto com o capitalismo é absolutamente necessário, é porque, à sua maneira, ele é uma formação que se estende sobre toda a superfície da terra, embora suas ambições não sejam territoriais. Estender o mercado não é conquistar a terra. [...] O capitalismo é efetivamente o que desterritorializa a terra, mas para seguir e controlar os fluxos de mercadorias, de trabalho e de dinheiro que se distribuem sobre ela em todas as direções; tal desterritorialização generalizada, própria do capitalismo, não se realiza sem suscitar as mais forçadas reterritorializações (2015:43).

\footnotetext{
${ }^{7}$ Para uma definição mais específica de espaços lisos e estriados, ver Mil Platôs.

${ }^{8} \mathrm{Em} O$ que é a filosofia, o plano de imanência é definido como o que "constitui o solo, absoluto da filosofia, sua Terra ou sua desterritorialização, sua fundação, sobre os quais ela cria seus conceitos.". (Deleuze; Guattari, 1992:44)
} 
Assim, a floresta de eucaliptos no Sapê do Norte devasta aquela terra, engolindo qualquer referência quilombola. As duas pessoas fotografadas na imagem descrita acima olham em volta e nada reconhecem. Elas caminham por uma ilha de árvores que nada têm de natural. Ao fazer da floresta de eucaliptos um modo de vida - ainda que forçado - esses indivíduos se relacionam com a região como espaço, que é moldado, transformado. Se o capital formatou o espaço, os quilombolas o remodelam, criando cavidades onde o guindaste não alcança. Onde há vida, há expressão - e a terra escuta.

\section{Carvão, o resíduo do resto: a resistência quilombola sobrevive}

Diante da imposição violenta por parte da indústria e do Estado, os moradores das comunidades do Sapê do Norte encontraram uma forma de subsistência: a produção de carvão. A partir da queima de restos de troncos de eucalipto em grandes fornos improvisados, eles conseguem o resíduo vegetal, que é vendido para outras regiões do sudeste do país através de um esquema não oficial, possibilitado pelo contato com atravessadores.

Evidentemente, a prática envolve problemas ambientais, legais e de saúde, o que marginaliza física e burocraticamente os quilombolas. Dessa forma, eles são simultaneamente absorvidos e excluídos do modelo econômico nacional e regional. Embora possua um contexto completamente diverso, esta situação contraditória, ambígua, encontra analogia na descrição do encontro entre Ameríndios e europeus feita por Viveiros de Castro em A Inconstância da Alma Selvagem. É interessante sublinhar que Viveiros dedica um capítulo inteiro aos "materiais do pensamento"com que são construídas as consciências subjetivas desses dois grupos sociais - O Mármore e a Murta: Sobre a Inconstância da Alma Selvagem explora estas duas texturas ao conceber a ideia de que os índios brasileiros eram "gente receptiva a qualquer figura mas impossível de configurar"(Viveiros de Castro, 2016:184) e que eram

como a mata que os agasalhava, sempre pronta a se refechar sobre os espaços precariamente conquistados pela cultura. [...] Esse gentio sem fé, sem lei e sem rei não oferecia solo psicológico e institucional onde o Evangelho pudesse deitar raízes. (Viveiros de Castro, 2016:185).

Ao evocar os Ameríndios não se pretende, nem tangencialmente, desconsiderar a historicidade específica de cada um dos corpos sociais (índios e quilombolas). Bruno 
Latour critica o cosmopolitismo defendido por alguns sociólogos precisamente pela pressuposição de que

o cosmos único cuja existência e sólida certeza poderia, então, proporcionar todos os aspectos para a construção da metrópole mundial da qual todos nós seríamos muito felizes de ser cidadãos. (2004:453, tradução nossa)

Constatação que reverbera o texto de James Clifford, feito dezesseis anos antes da crítica de Latour: "O modernista etnógrafo procura pelo universal no local, o todo na parte"(1988:4, tradução nossa). Espera-se, diante deste cenário, que fique explícita, no presente artigo, a coerência com a linhagem antropológica que não busca "o todo na parte“.

Portanto, ao trazer o exemplo de Viveiros de Castro, pretende-se, com toda cautela a respeito das questões apresentadas, sugerir uma das possíveis leituras para a situação ambígua dos quilombolas capixabas - entre a tentativa de inserção no sistema econômico, e a criminalização, a resistência, contra este mesmo sistema, em nome de seu próprio modo de vida: os quilombolas, neste caso, agem como mata, murta (ou sapê) e não como mármore.

A partir dessa constatação, é possível esboçar uma imagem da resistência das comunidades que seja configurada pela sobrevivência, e não somente pela memória. Sobre o conceito de cultura, necessário para a construção do que é entendido (ao menos no ocidente) como memória, Viveiros propõe:

\footnotetext{
Nossa ideia corrente de cultura projeta uma paisagem antropológica povoada de estátuas de mármore, não de murta: museu clássico antes que jardim barroco. [...] sobretudo, cremos que o ser de uma sociedade é seu preservar: a memória e a tradição são o mármore identitário de que é feita a cultura (2016:195).
}

Mais uma vez, o conceito coincide com seu significado literal. A sobrevivência, trabalhada por Georges Didi-Huberman através da recuperação dos estudos de Aby Warburg, se refere a uma força que perpassa imagens através do tempo. Ela se manifesta pelo que Warburg chamou de pathosformeln (fórmulas do páthos), cuja aparência é gestual. Este complexo conceito encontra no caso dos quilombolas do Sapê do Norte, uma formação material interessante: para sobreviver (fisicamente), eles utilizam um corpo que é, também, uma sobrevida; mais especificamente, uma sobrevida da sobrevida (o 
resíduo do resto).

Um fato curioso é a origem do o termo "sobrevivência"nos estudos de Warburg. Ele foi apropriado do conhecido antropólogo do século XIX, Edward Tylor (considerado o criador da antropologia cultural, chamada então de "ciencia da cultura“), que trabaIhava com o que nomeou de survivals, no livro Primitive Culture (1871). Tylor era um evolucionista cultural, e, evidentemente, sua teoria e método antropológicos apresentam diversos problemas, principalmente se observados fora do contexto do fim do século retrasado. Ainda assim, de acordo com Didi-Huberman, este evento indica a relação - na época inusitada - entre a história (campo de estudos de Warburg) e a antropologia. É precisamente neste encontro que as fotografias do projeto Cartografia Social das Comunidades Quilombolas e o Carvão no Sapê do Norte trabalham.

Uma das imagens (Figura 5) do projeto mostra a parte interna de um forno de carvão. O ambiente cavernoso é precariamente iluminado por três aberturas na parede, ao alto, que parecem ter o formato de tijolos - que talvez tenham sido retirados da estrutura -, e por uma abertura similar a uma porta, por onde entra uma figura esfumaçada, com contornos mal definidos, que deduzimos ser um homem. Ele empurra um carrinho, que contém pedaços de madeira. Dentro do local, na parte mais escura da imagem, uma outra figura, menos reconhecível que a primeira, pode ser vista. É impossível definir o que é este borrão - seria o fogo, cuja função é queimar os restos de eucalipto?

O efeito fantasmagórico criado pela imagem sugere uma presença humana efêmera, fugaz e duvidosa. O espectro que pode ser identificado na porta quase não carrega traços, nem volume, nem peso. É um resto humano. "A ideia de sobrevivência seria, no campo das ciências históricas e antropológicas, uma expressão específica do rastro."(Didi-Huberman, 2013:48). Estaria esse espectro, então, em processo de consumo e apagamento, como o fogo, no interior do forno? Ou, ao contrário, em formação, construção e reinvenção, e foi capturado pelo olho da câmera durante o momento de condensação, como uma molécula gasosa de água, no instante anterior a tornar-se líquida? Ou, ainda, seria sua imagem espectral um sintoma de sua impossibilidade em incorporar um corte no tempo, um instante? Estaria ele carregando em sua fluidez diversos tempos imcompossíveis, anacrônicos? 


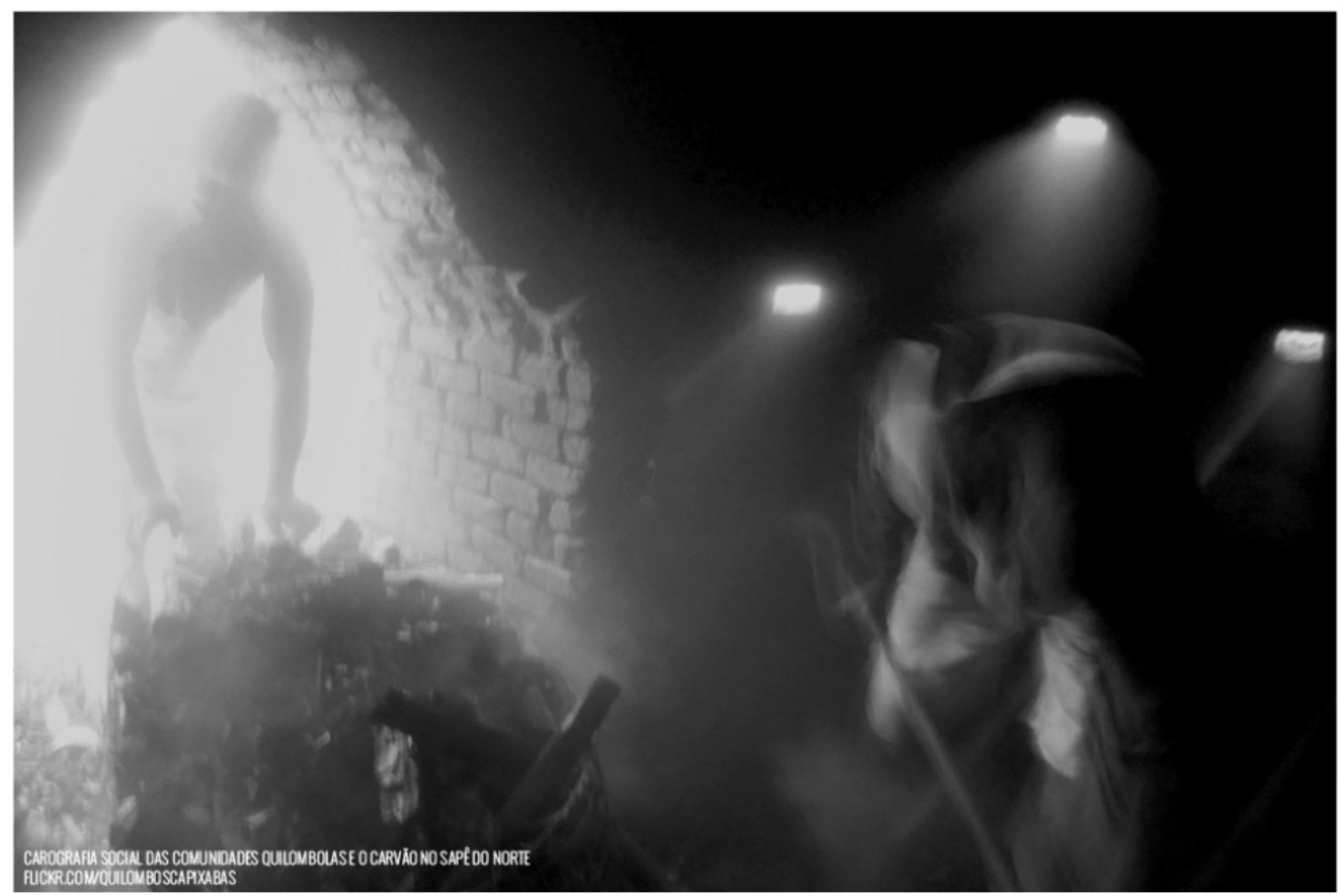

Figura 5. Fonte: Cartografia Social das Comunidades Quilombolas e o Carvão no Sapê do Norte, disponível em https://www.flickr.com/photos/quilomboscapixabas/9039268726/

Didi-Huberman formula em seu livro dedicado ao trabalho de Warburg:

O que faz sentido numa cultura, muitas vezes, é o sintoma, o não pensado, o anacrônico dessa cultura. Eis-nos já no tempo fantasmal das sobrevivências (2013:44).

O autor continua:

a "permanência da cultura" não se exprime como uma essência, um traço global ou um arquétipo, mas ao contrário, como um sintoma, um traço de exceção, uma coisa deslocada. (Didi-Huberman, 2013:47).

Estaria, portanto, manifesta de forma imagística, a emergência da história dos quilombos, de todos os escravos inconformados, desesperados, da terra violentada dos latifúndios, de todas as veias abertas - na linguagem de Eduardo Galeano ${ }^{9}$ - preenchidas com substratos de outrora? Apropriando a questão formulada por Didi-Huberman, "seria a via do sintoma a melhor maneira de ouvir a voz dos fantasmas?” (2013:48).

Giorgio Agamben defende que o terreno de uma nova biopolítica reside precisamente no resto, que ele configura como algo que sobra entre os processos de subje-

\footnotetext{
${ }^{9}$ Aqui, fazemos referência ao livro Las venas abiertas de América Latina (1971).
} 
tivação e de dessubjetivação. Sobre esta noção demasiadamente humanista, pode-se questionar ainda: estaria nova política mais próxima de uma cosmopolítica do que de uma biopolítica - como sugerem autores como Donna Haraway, Bruno Latour e Isabelle Stengers? Que outros restos, ou refugiados, para usar o termo de Haraway, compõem o tecido historiográfico e biológico? Aqui, é possível uma aproximação com o conceito de sobrevivência, que, segundo Didi-Huberman, é

a contraefetuação que não é nem o totalmente vivo nem o totalmente morto, e sim o outro género de vida das coisas que passaram e que insistem em nos assombrar (2013:167).

A ideia (com evidente traço bargsoniano) de que "o presente se tece de múltiplos passados" (Didi-Huberman, 2013:46), ou de que cada Agora tem o seu Então (Benjamin, 2006) - que também propõe um passado estratificado - talvez possam ser acrescidas de uma outra formulação: o presente se tece, também, de múltiplos possíveis futuros. E as imagens ocupam precisamente esta função - imaginar.

\section{Considerações finais}

Este artigo buscou propor uma camada interpretativa para as questões das comunidades quilombolas do nordeste do Espírito Santo, através da análise de algumas fotografias e das possibilidades imagísticas e imaginativas que elas materializam. Com o uso das teorias, principalmente, de Eduardo Viveiros de Castro, Gilles Deleuze e Felix Guattari (sobretudo sob a leitura de David Lapoujade), e Georges Didi-Huberman (enquanto principal explorador do pensamento de Aby Warburg), sugere-se uma investigação dos termos comunidade, espaço e sobrevivência, em interlocução com os autores citados, respectivamente. Esta proposta serve como uma alternativa para os já previsíveis conceitos (ao menos para o objeto escolhido) de filiação, território e memória.

Se a existência exige resistência, o processo indexical de apreendê-la produz potência de re-existir. As imagens abrem todas as possibilidades do devir. 


\section{Referências}

BRASIL. Constituição (2016). Constituição da República Federativa do Brasil. Brasília, DF: Senado. Disponível em http://www.senado.gov.br/atividade/const/con1988/ADC1988_12.07.2016/art_68_.asp, acesso em 03/janeiro de 2017

INCRA. (2014) Regularização de Território Quilombola: Perguntas e Respostas. Disponível em http://www.incra.gov.br/sites/default/files/incra-perguntasrespostas-a4.pdf, acesso em 03/janeiro de 2017

SILVA, S. (2013) Cartografia Social das Comunidades Quilombolas e o Carvão no Sapê do Norte. Disponível em https://issuu.com/rayzamucuna/docs/cartografia_web, acesso em 14/fevereiro de 2017

BEJAMIN, W. (2006). Passagens. Belo Horizonte: Editora UFMG

BUTLER, J. (2009). Frames of War. Brooklyn: Verso

CLIFFORD, J. (1988). The Predicament of Culture: Twentieth-Century Ethnography, Literature, and Art. Cambridge: Harvard University Press

COSTELLO, D. (2005). Aura, Face, Photography: Re-reading Benjamin Today. Em: BENJAMIN, A. (E.) Walter Benjamin and Art. Londres: Continuum. pp. 1-31

DELEUZE, G. (2000). Diferença e Repeticão. Lisboa: Relógio D’Água

DELEUZE, G.; GUATTARI, F. (1995). Mil Platôs: Capitalismo e Esquizofrenia. São Paulo: Editora 34 . (1992). O que é a Filosofia?. São Paulo: Editora 34

DIDI-HUBERMAN, G. (2013). A Imagem Sobrevivente: História da Arte e Tempo dos Fantasmas. Rio de Janeiro: Contraponto

GALEANO, E. (1971) Las venas abiertas de América Latina. Montevideo: Siglo XXI Editores

HARAWAY, D. (2015) Anthropocene, Capitalocene, Plantationocene, Chthulucene: Making Kin. Em: Environmental Humanities, v. 6, pp 159-165

LAPOUJADE, D. (2015) Deleuze, os Movimentos Aberrantes. São Paulo: n-1 edições LATOUR, B. (2004) Whose Cosmos? Which Cosmopolitics?: Comments on the Peace Terms of Ulrich Beck. Em: Common Knowledge, v. 10, n. 3, pp 450-462

MOORE, J. (2014). The Capitalocene. Binghamton: Binghamton University

NANCY, J. (2000). La Comunidad Inoperante. Santiago de Chile: Escuela de Filosofía Universidad ARCIS

PELBART, P. (2007). Elementos para uma Cartografia da Grupalidade. Em: Próximo Ato. São Paulo: Itaú Cultural

STENGERS, I. (2010). Cosmopolitics. Minneapolis: University of Minnesota Press

VIVEIROS DE CASTRO, E. (2016). A Inconstância da Alma Selvagem. São Paulo: Cosac Naify 
(2015). Metafísicas Canibais: Elementos para uma Antropologia Pósestrutural. São Paulo: Cosac Naify

VIVEIROS DE CASTRO, E.; DANOWSKI, D. (2014). Há um Mundo Por Vir? Ensaio Sobre os Medos e os Fins. Florianópolis: Cultura e Barbárie Editora 